\title{
The Influence of an Information Environment on Construction Organization's Culture: A Case Study
}

\author{
Kenneth T. Sullivan, ${ }^{1}$ Dean T. Kashiwagi, ${ }^{1}$ and Nathan Chong ${ }^{2,3}$ \\ ${ }^{1}$ Del E. Webb School of Construction, Arizona State University, Tempe, AZ 85287-9309, USA \\ ${ }^{2}$ Facility Life Cycle Management Division, U.S. Army Medical Command, San Antonio, TX 78209, USA
}

${ }^{3} M \nLeftarrow R$ Facility Concepts, San Antonio, TX, USA

Correspondence should be addressed to Kenneth T. Sullivan, kenneth.sullivan@asu.edu

Received 1 April 2009; Revised 20 July 2009; Accepted 28 August 2009

Recommended by Serji Amirkhanian

\begin{abstract}
Construction professionals have identified public contract law and bureaucratic procurement/contract offices as a source of problems in the construction industry. The culture within the United State's Federal Government Acquisitions is based on the Federal Acquisition Regulations (FARs) and its interpretation, often placing organizations/agencies in the price-based environment and continuously resulting in poor performance. The United States Army Medical Command (MEDCOM) (approximately $\$ 100 \mathrm{M}$ in construction renovation awards per year) attempted to overcome this obstacle through a partnership with the Performance-Based Studies Research Group (PBSRG) at Arizona State University. The MEDCOM implemented the information environment portion of the Performance Information Procurement System (PIPS) into Indefinite Delivery Indefinite Quantity (IDIQ) contracts through the specifications. Without controlling the various contract/procurement processes, the developed information environment stimulated an atmosphere of accountability to all parties involved, while reducing the client's internal bureaucratic resistance. The concept has met with preliminary success, minimizing construction management issues by over $50 \%$, raising owner satisfaction by $9 \%$, resulting in $99 \%$ of projects ending with no contractor-generated change orders, and assisting MEDCOM leadership in measuring the performance of their infrastructure revitalization program.
\end{abstract}

Copyright ( $) 2009$ Kenneth T. Sullivan et al. This is an open access article distributed under the Creative Commons Attribution License, which permits unrestricted use, distribution, and reproduction in any medium, provided the original work is properly cited.

\section{Introduction}

The US Army Medical Command (MEDCOM) uses the Corps of Engineers (COEs) contracting/procurement offices to deliver approximately $\$ 100 \mathrm{M}$ of construction per year (maintenance, repair, and modification). The MEDCOM was introduced to the Performance Information Procurement System (PIPS) research, a best value approach to construction procurement, supported by the Performance Based Studies Research Group (PBSRG) at Arizona State University (ASU). The MEDCOM identified their organization and environment as a price-based environment producing low-performance results and characteristics. They were attracted to the extensive testing and documentation of the PBSRG that supported the idea that theoretical concepts, processes, and structures based on leadership principles (accountability, alignment, performance measurement, and value based), rather than management principles (control, direction, no performance measurements, and price based), would optimize the delivery of construction (Kashiwagi et al. [1]) as well as the recognized bureaucracy of the COE (Wilson [2]).

This paper focuses on identifying the differences between the price-based and value-based environments, the implementation of best value concepts by MEDCOM, the results of the implementation, and the potential of information environments in the delivery of construction and organizational efficiency. In the research, no procurement is performed; only the application of an information environment and the culture transformations required is addressed.

\section{Differential between the Price-Based and Value-Based Environments}

The difference between the price-based and value-based environments is illustrated in the Construction Industry 


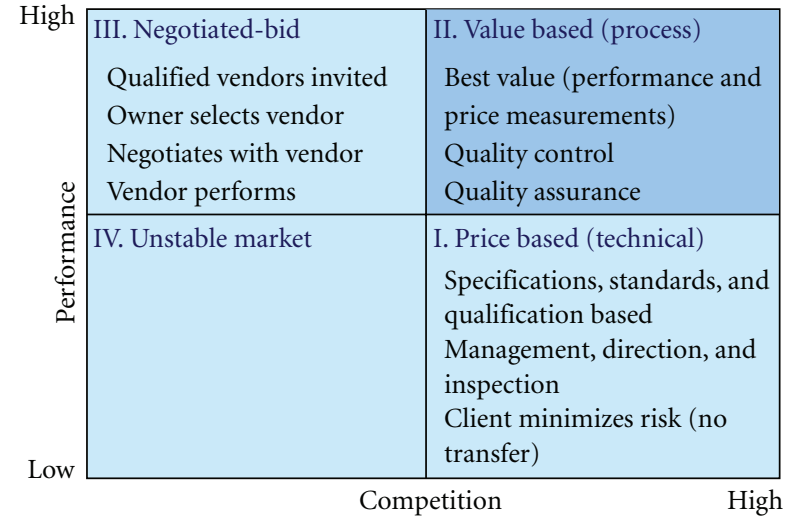

Figure 1: Construction industry structure (CIS) (Kashiwagi [4]).
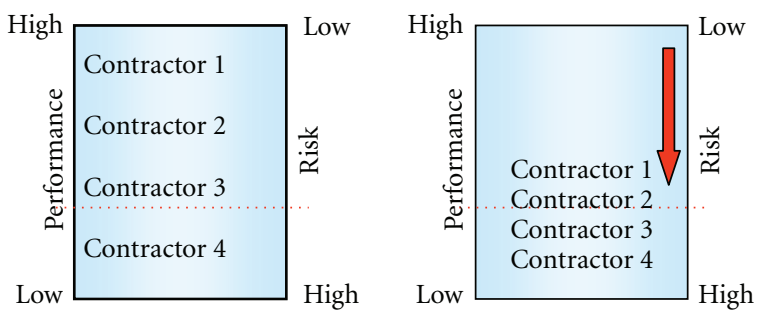

FIGURE 2: Impact of price-based bidding: increase of risk (Kashiwagi [4]).

Structure (CIS) diagram (Figure 1). The best value environment focuses on securing the best value vendor for the owner by considering the vendor's past performance, ability to identify and minimize risk, preplanning foresight, and project knowledge. It transfers all project risk to the outsourced expert, requiring the contractor to use their skill to fulfill the intent of the owner, and minimizes controlled risk at the beginning of the project. It forces accountability between all parties and benefits vendors with foresight, experience, skill, and efficiency. It provides an environment that maximizes contractor profit, while minimizing owner resources (Guo [3]).

In contrast, the price-based environment focuses on using minimum standards to define the requirement of the contract, in order to ensure that the minimal requirement is met. Due to its concentration on price, it encourages the contractors and vendors to translate the minimum requirement to a maximum, in attempts to lower the quality of the delivered product to gain the competitive advantage. The price-based environment gives inexperienced contractors the competitive advantage over experienced contractors, thus driving the experienced contractors to move from a position of minimizing risk to a position of ignoring project risk (PSC 2003, Statistics, Trends, Market, Analysis 2003).

This trend, which is clearly demonstrated in Figure 2, has many ramifications. The price-based approach penalizes contractors who carefully preplan, understand the scope of the project, and price out the project. This discourages the use of expertise, asking the contractor/vendor to price only what is written, ignoring the owner's intent. It also motivates contractors to take the lowest price at the last minute, not knowing whether they are meeting the specifications. Additionally, the price-based approach encourages all manufactures to ensure that their products meet only the lowest possible quality to get the largest possible volume sales of contractors trying to get the lowest price. On an industry level, the price-based approach promotes the bypass of education and personnel training, leading to a critical shortage of trained personnel. This results in the contractor relying on the client to manage, direct, control, and inspect, and become reactive instead of proactive. Overall, it leads to poor construction performance (not on time, not on budget, and not meeting the client's expectations).

2.1. Relative Analysis of the Two Environments. A relative analysis of the two environments (price-based and best value) leads to the following deductive conclusions. Performance can only occur when risk is transferred to an entity that has the capabilities of minimizing the risk. The best value environment ensures the selection of a qualified contractor through the use of performance information filters. The majority of the owner's resulting risk in this environment is the interface or the seam between the client and the contractor, or in other words the risk that the contractor does not directly control (See Figure 3).

Alternatively, the price based environment passes risk to the contractor with the lowest price, without ensuring that they can minimize the risk. When risk is transferred to a party unable to minimize the risk, the party must be managed, inspected, and controlled. In consequence, the owner's risk in the low-price environment is the potential that the minimally trained, managed, and directed contractor/vendor may not do what they are directed to do (see Figure 3). The price-based environment has reflected this, in a heavy overhead for transaction costs relating to management, direction, control, inspection, and communications that would be eliminated if the client's process were more efficient. This has also translated to a higher requirement of people needed to maintain the system (due to inefficiency of the process).

Accordingly, there is more confusion in the price-based environment due to the management, decision making, unrealistic expectations, attempts to control others, use of leverage (making a party do free work or work that they are incapable of doing), and the lack of performance information of key individuals, contractors, and the client's personnel. Without simple, easy-to-understand measurements, that consider the vendor's capabilities, the price-based environment remains adversarial, where every participant, regardless of who they work for, protects themselves, before they protect the company they work for, or the client/user the construction is being built. These characteristics are supported by documentation of construction delivered by the price-based environment (Butler [5]; Doree [6]; FitzGibbon and Golding [7]; Guo [3]; Markus [8]; NDU [9]; Post [10]; [11]). 

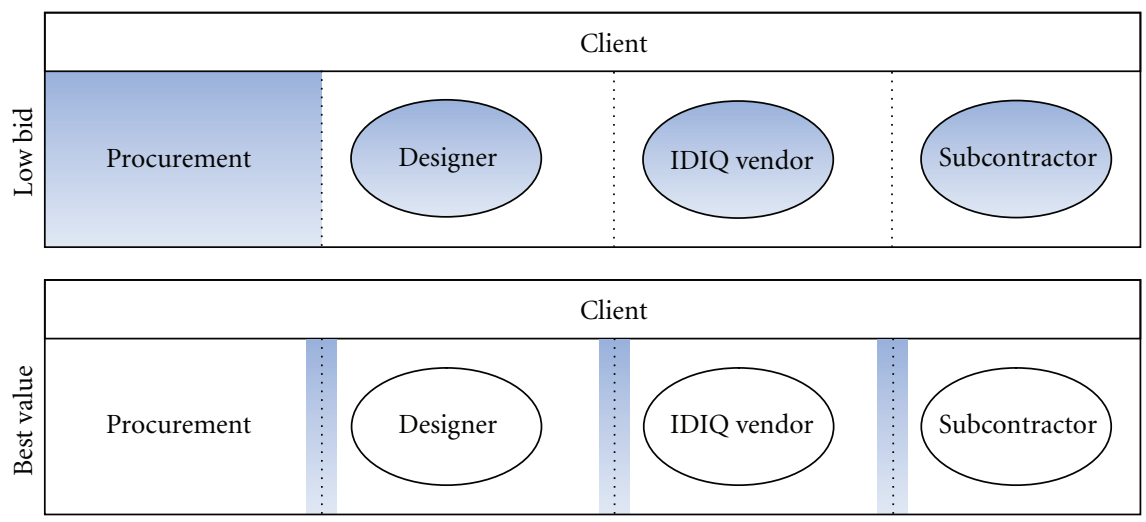

Risk

Interface

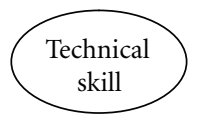

FIGURE 3: Difference in risk between price-based and best-value environments.

\section{Best Value Performance Information Procurement System}

Over the past thirteen years, PBSRG has been testing best value procurement using an information-based Performance Information Procurement System (PIPS) in both the public and private sector. The results and measurements of PIPS have validated the best value concepts. Of the 480 tests completed and $\$ 500 \mathrm{M}$ of procured construction, 98 percent of projects finished on time, on budget, while meeting client expectations. The process has minimized the management efforts of client construction managers by 80 to 90 percent (Kashiwagi et al. [12], Sullivan et al. [13]) and allowed the project managers to increase their delivery of projects by up to tenfold (State of Hawaii [11]). The process was awarded the 2005 Corenet Global Innovation of the Year Award for testing at Harvard University and the 2000 Tech Pono Award for the testing at the State of Hawaii.

3.1. Best Value PIPS Process. The Best Value PIPS process (shown in Figure 4) is composed of three primary steps:

(1) selection phase (Filter 1-4): identification of the best value

(2) preplanning/quality control phase (Filter 5): forcing the best value to preplan and minimize risk that they control and do not directly control through a PIPS Quality Control Plan or Risk Plan and schedule,

(3) risk management phase (Filter 6): management of the construction project through risk minimization.

Selection Phase. The selection phase attempts to differentiate the performance and expertise of competing vendors. This is done through the collection of each contractor's past performance information (from key individuals as well as the general contractor and critical subcontractors), identifi- cation of project risk out of their control, plans to minimize uncontrolled risks, value-added options, and interview ratings. It is important to note that if the contractors cannot differentiate themselves through their performance, there is nothing wrong with awarding the project based on the best price (as the contractors proved that they are all the same). The client should not make decisions to assist any contractor to become competitive. No contractor should be assisted by being given a second chance, redoing their cost estimate, or given information from other contractors that could possibly make them more competitive. In best value, every contractor is competitive, and every contractor has a chance to differentiate themselves without biased assistance from the client's representative.

Preplanning/Quality Control Phase. The Best Value PIPS process forces the "best value" contractor to take their price, risk assessment/value-added plan, and interview statements into the second phase of Preplanning/Quality Control. In the preplanning/PIPS Quality Control Phase, the contractor concentrates on minimizing the project risks. A schedule listing the major milestones in the project is developed, along with a list of client action items, or a list of tasks, decisions, and so forth needed from the client (with dates). A QC plan is also compiled by the contractor which includes a list of risks out of the contractor's immediate control in conjunction with a detailed plan to minimize each risk. Technical risks are not included, as the contractor minimizes risks that they control by meeting the requirements of the specification. After the owner has evaluated the contractor's uncontrollable risks; agreed to the accompanying plans to mitigate the risks; had his risk and concerns, as given to the contractor, addressed and mitigated with risk minimization plans; has agreed to the dates and client action item requirements; and in total is satisfied with the preplanning performed by the 


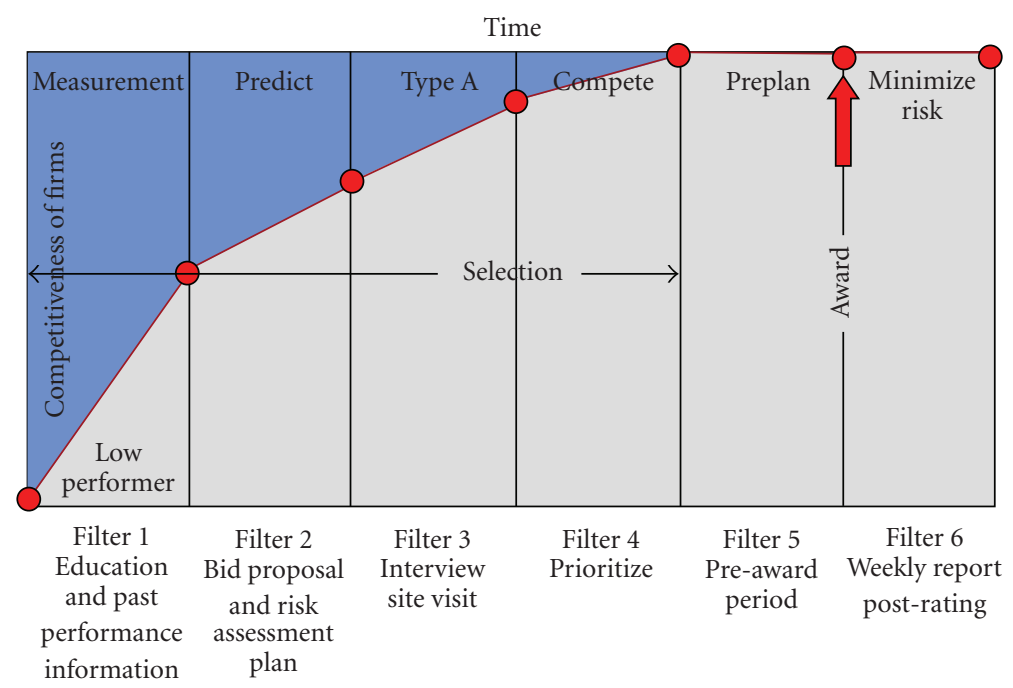

FIgURE 4: Best value natural selection (Kashiwagi [4]).

contractor, will the contract be awarded? If the client is not satisfied, the client can move the next highest rated vendor.

In having the "best value" contractor create a QC plan, the authors are making the assumption that it is much easier to have the contractor identify risks to the project that they do not control, than it is to identify all the risks that the contractor does control. It also transfers the risk to the contractor by having the contractor identify the risks. The authors are also assuming that a nonexperienced contractor will not feel comfortable managing the risk in this situation, due to their inability to efficiently identify the risks that they do not control. This is because

(1) experienced contractors know the roles and impact of different participants (Anvuur and Kumaraswamy [14]),

(2) inexperienced contractors are reactive, and only know their risk in terms of what they are supposed to do (Zack [15]),

(3) experienced contractors do not need to be managed and directed (Buckshon [16]).

Risk Management Phase. Once the project has been initialized, the contractor enters the Risk Management Phase. Every week during project execution, the contractor is required to submit a Quality Assurance (QA) plan and Weekly Report to the owner. The QA plan is a checklist of the risks identified in the previous phase that ensures that each risk is being monitored and minimized according to the directives included in the QC plan. If the risk cannot be minimized according to client-preapproved QC efforts, the risk is reported on the weekly report along with unforeseen risks adversely impacting the schedule or budget. The weekly report identifiesthe following: (1) why the contractor was not able to minimize the risk; (2) what or who is the source of the risk; (3) what needs to be done by the source of the risk to minimize the risk; and (4) what the impact to the project will be in terms of time, cost, and expectation. If the contractor
Unforeseen risks

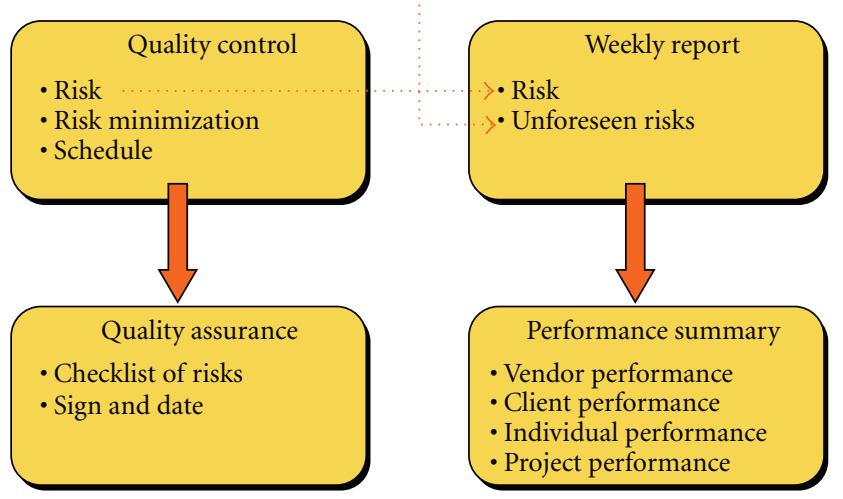

FIGURE 5: Information environment.

has done all that they can to minimize the risk, the client is then obliged to pay for additional time and effort. Figure 5 shows the QC Plan, components, the QA checklist as derived from the QC Plan and the flow of risk identification to the weekly risk report. From the weekly risk report information, the system can generate a director's report that gives the performance of the project and various system participants.

The preplanning, quality control, and measurement process transfer the control and risk to the contractor, who then uses the mechanism of the weekly report to make all parties accountable through communication, coordination, and additional preplanning. It is by contract, and in the best interest of the contractor, to report the risks on the weekly report. The QC plan, QA checklist, and weekly report are all documents that identify the risks that the contractor does not control, protecting the performing contractor.

The selection process ensures the procurement of the best value contractor and the transfer of all project risk to the contractor. The QC plan and the weekly risk report then defend the high performing contractor by identifying risks out of the contractor's control and the contractor's 


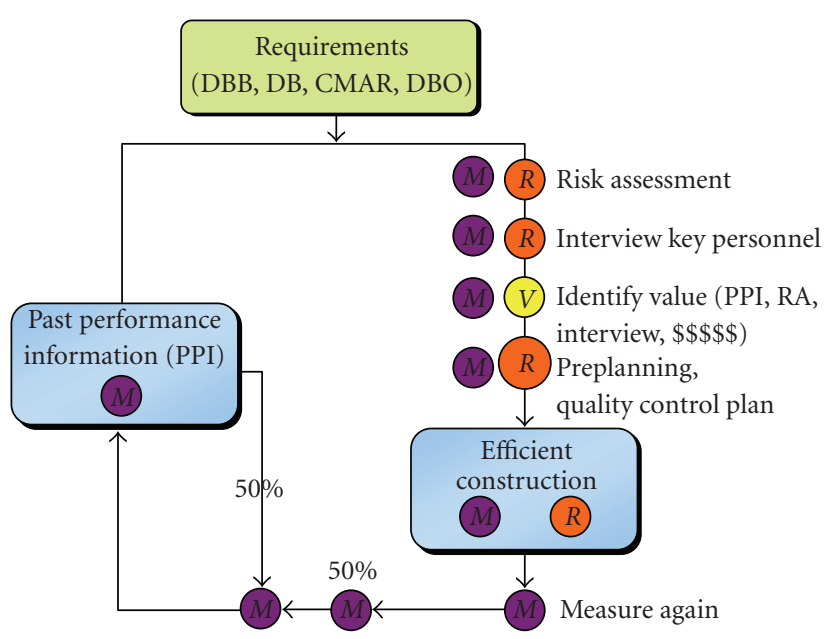

(V) Identify value
(R) Minimize risk
(M) Self measurement

Figure 6: Best value DMAIC closed loop (Kashiwagi [4]).

limited abilities to impact the risk. Because it is reviewed by the client's representative, the information is usually very accurate. The QC plan, QA checklist, weekly report, and schedule also help to regulate the contractor's work. All the elements are incorporated into the contractor's contract upon award. At the end of the project, the contractor is rated by the owner, and the rating modifies the past performance rating of the contractor by $50 \%$ (Figure 6 ).

Information System. The owner is able to compile a group of individual contractor weekly reports (spreadsheets submitted to the client weekly) into a Director's Report (Table 1) which can give a Facility/Construction director valuable measurements of risk/performance for the organization as a whole as well as a prioritization of the risks. The Director's Report also allows for the comparison of contractors, project managers, project integrators, inspectors, or design professionals involved in the projects. The report provides accurate, timely risk/performance information that disables bureaucracy and identifies where risk is being created. For the first time, it gives a director a simplistic information system with minimal maintenance that deters nonperformance by highlighting nonperformance quickly and accurately.

In the report, the majority of the information itself is a simple sum or average of the data from the weekly risk reports (one is submitted for each project each week). The only algorithmic-based information is the risk number, which is simply computed as

$$
\begin{aligned}
& \text { Risk Number } \\
& \begin{aligned}
= & (11-\text { Project Satisfaction Rating }) \\
& *(1+\% \text { over budget }) *(1+\% \text { over schedule }) .
\end{aligned}
\end{aligned}
$$

\section{Proposing Best Value to the COE}

MEDCOM proposed to the COE that by selecting Indefinite Delivery Indefinite Quantity (IDIQ) contractors and award task orders based on the following best value principles and process, the efficiency and performance of construction procurement could be increased. However, the COE decided that there were too many changes and believed that some of the changes were not legally allowed (this is a point of disagreement between several COE agencies). Some of the changes/misunderstandings included the following.

(1) The COEs were under the misunderstanding that the process was proprietary and that Arizona State University (ASU) would be running their procurement. It is illegal for the COE to outsource its procurement [17].

(2) The COE felt that non-COE personnel could not be on the selection team.

(3) The Army Federal Acquisition Regulation (AFAR) would not permit the use of weights and numbers in a best value selection [17].

(4) The preaward phase, where the best value contractor creates their quality control (QC) plan, quality assurance (QA) checklist, and schedule, was not allowed by the Federal Acquisition Regulation (FAR), due to the requirement to have discussions with all the offerors before the award of the contract [17].

(5) The existing COE quality assurance plan was verification of the technical requirements, while the QC plan for the Best Value PIPS was to minimize risk that the contractor did not control.

The above points of resistance were either misunderstandings or items that could easily be adapted to ensure regulation compliance. The current Director of the Facility Life Cycle Management Division at MEDCOM realized that the cultural change required to implement Best Value PIPS in the COE was too drastic, and he proposed to obtain higherperformance results another way. With assistance from the Performance-Based Studies Research Group, the Director of MEDCOM proposed to overcome the COE's resistance to change and policies by using the theoretical concepts of a best value environment as a component of the technical requirements/specifications of the IDIQ contract that the COE would award to the IDIQ contractor. It was also proposed that the best value environment and an information environment as presented by Kashiwagi [4] were the same, and therefore an information environment required in the specifications would mimic a best value environment without altering the procurement system. It was further hypothesized that the contractors would understand that an information environment would maximize their efficiency and profit and therefore be in their own best interests. This realization coupled with the information environment would increase the performance of the IDIQ contractors.

The director decided to create a best value information environment, embed within the technical specifications of 
TABLE 1: Weekly report and director's report.

(a) Individual project performance from weekly report

\begin{tabular}{|c|c|}
\hline \multicolumn{2}{|l|}{ Unforeseen (UF) \& Owner (0) Risk } \\
\hline \# UF Risks affecting budget/schedule & 0 \\
\hline Days delayed (Calendar) & 0 \\
\hline Additional costs & 0 \\
\hline \# 0. Risk affecting budget/schedule & 1 \\
\hline Days delayed (Calendar) & 0 \\
\hline Additional costs & $\$ 2.000 .00$ \\
\hline \multicolumn{2}{|c|}{ Above risks include potential and resolved } \\
\hline \multicolumn{2}{|l|}{ Contractor risks } \\
\hline \# of Unaddressed/Overdue Risks & 1 \\
\hline \# Unrated risks & 0 \\
\hline \# Risks affecting budget/schedule & 2 \\
\hline Risks to schedule (calendar days) & 15 \\
\hline Risk to cost & $\$ 1.000 .00$ \\
\hline Contractor satisfaction rating & 10 \\
\hline \multicolumn{2}{|c|}{ Above risks include potential and resolved } \\
\hline \multicolumn{2}{|l|}{ Overall current status } \\
\hline Days delayed (calendar days) & 5 \\
\hline$\%$ Delayed & $0.8 \%$ \\
\hline Contractor \% delayed & $0.8 \%$ \\
\hline Additional costs & $\$ 2.000 .00$ \\
\hline$\%$ Over award & $9.2 \%$ \\
\hline Contractor \% over award & $0 \%$ \\
\hline Project satisfaction rating & 10 \\
\hline Risk number & 1.16 \\
\hline \multicolumn{2}{|c|}{ Above schedule and budget additions include only resolved risks } \\
\hline
\end{tabular}

(b) Overall organization performance

\begin{tabular}{|c|c|}
\hline Division overview & $25 / 9 / 2009$ \\
\hline Original projects budget & $\$ 585999296.63$ \\
\hline Current estimated cost & $\$ 613872042.82$ \\
\hline Estimated cost over budget & $\$ 27872746.19$ \\
\hline \multicolumn{2}{|c|}{ Project overview } \\
\hline Total number of projects & 194 \\
\hline$\%$ projects on time & $43 \%$ \\
\hline Number of jobs delayed & 111 \\
\hline$\%$ projects on budget & $54 \%$ \\
\hline Number of jobs over awarded budget & 16 \\
\hline Number of projects missing owner ratings & 0 \\
\hline \multicolumn{2}{|c|}{ Average project } \\
\hline \multicolumn{2}{|l|}{ Project schedule length in days } \\
\hline Project budget & $\$ 3020614.93$ \\
\hline$\%$ over awarded budget & $4.76 \%$ \\
\hline$\%$ over budget due to owner & $3.42 \%$ \\
\hline$\%$ over budget due to contractor & $0.03 \%$ \\
\hline$\%$ over budget due to unforeseen & $1.31 \%$ \\
\hline Average length of project & 529 \\
\hline$\%$ Delayed & $24.07 \%$ \\
\hline$\%$ Delayed due to owner & $17.21 \%$ \\
\hline$\%$ Delayed due to contractor & $1.89 \%$ \\
\hline$\%$ Delayed due to unforeseen & $4.97 \%$ \\
\hline
\end{tabular}


(b) Continued.

\begin{tabular}{lc}
\hline Division overview & $25 / 9 / 2009$ \\
\hline Number of risks & 2.00 \\
Number owner generated risks & 1.36 \\
Number of overdue risks & 0.52 \\
Owner rating & 9.36 \\
Risk number & 2.86 \\
\hline
\end{tabular}

(c) Risk ranking in projects

\begin{tabular}{lcc}
\hline & Top 10 risk ranking projects 9/25/2009 & Risk number \\
\hline 1 & Project & 42.63 \\
2 & Addition to Third Floor Womans Health Care Suite & 28.98 \\
3 & Replace Hot Water Converters & 28.09 \\
4 & Construct Rollup Connections for Boilers \& Chillers & 18.22 \\
5 & Security Repairs & 13.10 \\
6 & Misc. Medical Repair Projects '08 & 12.73 \\
7 & Rep, Reconf for TBI Program & 12.66 \\
8 & Bathroom Conversions, Bldg 9200 \\
9 & Renew Health Clinic, Building 990 & 11.01 \\
10 & Repair AHU Number 2 and Number 3 & 10.73 \\
\hline
\end{tabular}

(d) Comparing vendor performance

\begin{tabular}{|c|c|c|c|}
\hline Contractor overview & Contractor A & Contractor B & Contractor C \\
\hline Total awarded budget & $\$ 1202511$ & $\$ 474170$ & $\$ 4015198$ \\
\hline Current cost & $\$ 4907721$ & $\$ 487924$ & $\$ 4357671$ \\
\hline Over budget & $\$ 3705210$ & $\$ 13754$ & $\$ 342473$ \\
\hline \multicolumn{4}{|c|}{ Project overview } \\
\hline Total number of projects & 1 & 1 & 1 \\
\hline$\%$ Projects on time & $0 \%$ & $0 \%$ & $0 \%$ \\
\hline Number of Jobs delayed & 1 & 1 & 1 \\
\hline$\%$ Projects on budget & $0 \%$ & $0 \%$ & $0 \%$ \\
\hline Number of Jobs over awarded budget & 1 & 1 & 1 \\
\hline \multicolumn{4}{|c|}{ Average project } \\
\hline Number of Risks per job & 3.00 & 3.00 & 5.00 \\
\hline Owner generated risks & 0.00 & 3.00 & 5.00 \\
\hline Number of overdue risks & 1 & 0 & 1 \\
\hline$\%$ Over awarded budget & $308.12 \%$ & $2.90 \%$ & $8.53 \%$ \\
\hline$\%$ over budget due to owner & $0.00 \%$ & $2.90 \%$ & $8.53 \%$ \\
\hline$\%$ over budget due to contractor & $0.00 \%$ & $0.00 \%$ & $0.00 \%$ \\
\hline$\%$ over budget due to unforseen & $308.12 \%$ & $0.00 \%$ & $0.00 \%$ \\
\hline Number of Days delayed & 601 & 99 & 183 \\
\hline Number of days delayed due to owner & 0 & 99 & 183 \\
\hline Number days delayed due to contractor & 0 & 0 & 0 \\
\hline Number days delayed due to unforseen & 601 & 0 & 0 \\
\hline Owner rating & 10.00 & 6.71 & 6.63 \\
\hline Risk number & 13.10 & 6.16 & 6.09 \\
\hline
\end{tabular}

MEDCOM, and then measure the results. Through measurement, accountability would be realized and the information environment would in essence encourage the contractors to improve and perform. The environment would make every participant accountable as all would be measured (contractors, MEDCOM personnel, COE personnel, etc.). Performance-based specifications have been proposed before [18]; however, simultaneously using specifications with 
minimum standards, best value concepts, and an information environment is a new contribution to the delivery of construction.

This hypothesis makes one of the following assumptions.

(1) A lower performing contractor can become a high performer by using a best value/information structure.

(2) A contractor who competes on a specification that requires them to report the delivering of construction through a best value/information environment structure will educate/train their personnel to act in a manner to deliver performing results.

(3) An information environment forces accountability regardless of the selection process.

\section{Implementing Best Value PIPS through Specification}

The Best Value PIPS process is flexible and can be adjusted for implementation on Design-Build, CM@Risk, DesignBid-Build, IDIQ contracts, or on designers (Kashiwagi [4]). In order to implement Best Value PIPS into the US Medical Command (MEDCOM), the system was adjusted in order to assure compatibility with the FAR and the AFAR Supplement.

The term "best value" is mentioned 34 times, and the term "low bid" is mentioned 19 times in the FAR. Best Value means the "expected outcome of an acquisition that, in the estimation of the Government, provides the greatest possible benefit to the requirement (FAR 2.1)." The benefits include (FAR 102.2(b)) the following to

(1) satisfy the customer in terms of cost, quality, and timeliness of the delivered product or service by, for example,

(i) maximizing the use of commercial products and services,

(ii) using contractors who have a track record of successful past performance or who demonstrate a current superior ability to perform,

(iii) promoting competition;

(2) minimize administrative operating costs;

(3) conduct business with integrity, fairness, and openness.

The intent of the Federal Acquisition Regulation [17] is to use a method that will bring the government the "best value," whether or not the strategy has been addressed by the government. It explicitly states that "Absence of direction should be interpreted as permitting the Team to innovate and use sound business judgment that is otherwise consistent with law and within the limits of their authority." In the delivery of construction, the FAR recommends sealed bids. However, in FAR 36.103b and 6.04(b)(1), it states that if the use of sealed bids cannot effectively deliver the best value, the request for proposal process using other criteria than price can be used.

The FAR also addresses the use of the PIPS filters of past performance (FAR 15.305(a)(2)), the risk assessment plan/value added plan (FAR 15-305(a)(3)(i)), and the interview (FAR 15.102). The FAR addresses prioritization of alternatives by stating that "An agency shall evaluate competitive proposals and then assess their relative qualities solely on the factors and subfactors specified in the solicitation. Evaluations may be conducted using any rating method or combination of methods ..." However, the Army FAR Supplement states (5115.304) that "Evaluation Factors and Significant Subfactors must be qualitative (i.e., adjectival, colors, or other indicators, but not numbers). Numerical weighting is not an authorized method of expressing the relative importance of these factors and subfactors."

Therefore, when selecting a contractor, AFAR Supplement Best Value process must not use either weight or the ratings on any of the evaluation factors must have qualitative ratings. The impact of this policy is the lack of transparency but also prevents protests due to the inability or difficulty to challenge a subjective, nontransparent system. The downside to this type of system is that it motivates owner representatives to make decisions instead of allowing the contractors to determine who gets the project based on a preset system that is very predictable. However, Best Value PIPS can still be run using qualitative ratings on past performance, risk assessment/value added submittal, and interviews.

As a result of the FAR and AFAR Supplement, the following changes were made.

(1) The preplanning quality control period is performed during a preconstruction period after the award of the contract.

(2) The technical and nontechnical concerns of the client/user are given to all contractors.

Accordingly, the MEDCOM incorporated the following into their specifications:

(1) checklists that forced the use of preplanning and a quality control plan that minimized the risk that the contractor did not control; these checklists applied to both the design stage (work plan) and the construction stage;

(2) the use of a quality control plan (focused on risk identification and minimization), a quality assurance checklist, a schedule, and a weekly reporting system tracking the risk that the contractor did not control.

The MEDCOM then used the information system to compile multiple weekly risk reports and develop current performance barcodes or measurements for the entities involved. Performance measurements were computed for thecontractors (Table $1(\mathrm{~d})$ ), as well as the COE project managers, the MEDCOM project integrators, and the procurement offices. The numbers shown are the summary averages from the weekly risk reports for the individuals or offices projects. 


\section{Preliminary Test Results}

The MEDCOM performance before the test was run included the following.

(1) Frequent problems are presented to the MEDCOM construction manager.

(2) Fifty percent of the projects are on time and on budget.

(3) Contractors on 80 percent of the projects do not preplan and minimize risk.

(4) For half of the projects that are delayed, the reason for the delay is unclear.

(5) None of the contractors had their own QC plan, QA checklists, and weekly risk report that protected themselves and the clients.

(6) No contractors showed interest or initiative in understanding the best value concepts.

The information environment was initially pilot tested on six projects (no procurement was performed, only application of the information environment), and within eight months it was expanded to encompass 87 projects. In the past year it has been implemented on all projects with a budget value greater than $\$ 300000$ (USD), which is at the time of publication, a total of 189 projects with a construction value of over \$289000 000 (USD). The information environment allowed the owner to identify the source of project risk and change orders. It was found that $88 \%$ of cost and schedule runs were due to the owner, while $12 \%$ was due to the contractor. Also, the current estimate of the number of projects with performance issues requiring high-level assistance is 15 (out of 189) or eight percent. Out of these projects, only 5 of them are due to the contractor problems.

Other results include

(1) $99 \%$ of projects currently on budget (no contractor changes to budget),

(2) average contractor budget increase is $.03 \%$,

(3) $95 \%$ of projects currently on time (no contractor changes to schedule),

(4) average owner satisfaction rating increase of $9 \%$, from 8.99 to 9.80 owner satisfaction on completed projects (1-10 scoring, 10 being the highest),

(5) average time to resolve a project risk decreased by $54 \%$,

(6) the contractors began to personally invest in the education and training of best value procurement, introducing and encouraging nongovernment clients to use the PIPS system.

The implementation of the information environment increased overall owner satisfaction ratings for each of the five contractors involved by up to $64 \%$. The performance order or ranking of the five primary contractors was not affected; however the overall contractor performance increased substantially, averaging 9\%. Throughout the transformation, the contractors began focusing on the performance of the project, in terms of the minimization of owner risk, rather than project specifications. This was confirmed through contractor educational meetings, newsletters, interviews, and emails. An excerpt from one contractor newsletter read "The primary goal of the PIPS process is to identify and mitigate early on any risk/problem that may have the potential to keep the task order from being completed on time and within budget ... It is intuitively obvious that we need to seriously concentrate on improving the "service" that we are providing to the Government."

Once the IDIQ contractors had been educated in the Best Value process, they began to realize that it would assist them to be more efficient, make the client's/user's representatives accountable, and maximize their profits without charging more (win-win). The contractors began to realize that the process was a very successful enterprise model that used best business practices, motivated their personnel to improve, and measured their own performance. The majority of the contractors began requesting their personal performance measurements.

The MEDCOM organization also noted the following preliminary results.

(1) Projects started with the best value environments have had no outstanding issues where the contractor is at fault.

(2) The information system has clearly and efficiently identified that the biggest source of risk are the client and procurement/contracting offices.

(3) There have been no disagreements or argument over the risk's source or the responsible entity, once it is identified by the process.

(4) Contractors are slowly learning the process of minimizing risk that they do not control.

(5) The submission of meaningful contractor quality control plans has been a challenge.

(6) The contractors and users have had a difficult time understanding the connection and use of the QC plan, QA checklist, and the weekly report.

6.1. Resistance to Change. The migration to Best Value is threatening to the status quo due to the following.

(1) Best Value/PIPS forces the government to release control to the outsourced vendor. It is difficult for procurement agents to release control.

(2) Increased efficiency threatens the procurement community, who may feel that their jobs are being replaced or eliminated.

(3) Cultural change often is accompanied by fear, manifested in resistance to change, not being open to logic/best practices, using the FAR and AFARS and interpreting new concepts as illegal, increasing transaction costs of other participants in the delivery chain, and not acting in the best interest of the government. 


\section{Conclusion}

The authors proposed that an information environment can be directed into the technical specifications without changing the procurement system and force best value practices. This hypothesis is dependent on the contractor using a QC plan that minimizes risk that they do not control. The use of the QC plan, QA checklist, weekly risk report, and information environment director's report, all of which are documented by the contractors, has provided MEDCOM with an accurate performance history of construction projects on a weekly basis. Preliminary results indicate that the more efficient environment has minimized nonperformance within MEDCOM and maximized the profit of the contractors (Welker [19]).

\section{References}

[1] D. T. Kashiwagi, K. Sullivan, M. Kashiwagi, N. Chong, and M. Pauli, "Reduced information flow maximizes construction performance," in Proceedings of the International Conference in the Built Environment in the 21st Century (ICIBE '06), Kuala Lumpur, Malaysia, June 2006.

[2] J. Q. Wilson, Bureaucracy: What Government Agencies Do and Why They Do It, Basic Books, New York, NY, USA, 2nd edition, 1991.

[3] Y. Guo, Cash flow and risk analysis: best value vs. low bid, M.S. thesis, Arizona State University, Phoenix, Ariz, USA, 2006.

[4] D. T. Kashiwagi, Best Value Procurement: How to Use Information System to Minimize Risk, Increase Performance, and Predict Future Success, Performance Based Studies Research Group, Phoenix, Ariz, USA, 2004.

[5] J. Butler, "Construction quality stinks," Engineering NewsRecord, vol. 248, no. 10, p. 99, 2002.

[6] A. G. Dorée, "Collusion in the Dutch construction industry: an industrial organization perspective," Building Research and Information, vol. 32, no. 2, pp. 146-156, 2004.

[7] J. Fitz-Gibbon and B. Golding, "Low bidder for Tappan Zee repair has history of overruns, litigation," The Journal News, March 2007.

[8] E. Markus, "Low bid alternatives," American City \& County, August 1997.

[9] NDU, "Government goals and rules: industry studies," March 2007.

[10] N. M. Post, "Building teams get high marks," Engineering News-Record, vol. 240, no. 19, pp. 32-39, 1998.

[11] “Hearings Officer's Findings of Fact, Conclusions of Law, and Decision," State of Hawaii Office of Administrative Hearings, Department of Commerce and Consumer Affairs, June 2002.

[12] D. T. Kashiwagi, J. Savicky, and D. Parmar, "Case study of the impact of specifications, construction management, and inspection on construction performance," in Proceedings of the 19th Annual Conference of the Association of Researchers in Construction Management (ARCOM '03), pp. 369-377, University of Brighton, Brighton, UK, 2003.

[13] K. Sullivan, J. Savicky, D. Kashiwagi, M. Perkins, and J. Grussing, "Transitioning to an information environment: performance research in large capital projects and facility management group," in Proceedings of the 4th International Conference on Construction in the 21st Century: Accelerating Innovation in Engineering, Management, and Technology (CITC-IV '07), Gold Coast, Australia, July 2007.
[14] A. M. Anvuur and M. M. Kumaraswamy, "Conceptual model of partnering and alliancing," Journal of Construction Engineering and Management, vol. 133, no. 3, pp. 225-234, 2007.

[15] J. G. Zack Jr., "Cost engineers and risk analysis impacting project owners," Cost Engineering, vol. 48, no. 12, pp. 3-5, 2006.

[16] M. Buckshon, "Complex bids: an industry challenge," GTA Construction Report, Ottawa Construction News, May 2007.

[17] Federal Acquisition Regulations (FAR), 15.306(d)(1) and (e)(1), 37.204, and 15115.304, January 2007, http://www.arnet .gov/far.

[18] Federal Acquisition Regulations (FAR), "Best Practices for Multiple Award Task and Delivery Order Contracting, Interim Edition," January 2007, http://www.whitehouse.gov/ omb/rewrite/procurement/interagency_acq/best_practices_ multiple_award_task_contracting.html.

[19] R. Welker, "Performance based general contractor," in Proceedings of the Best Value/Leadership Conference, Arizona State University, 2007. 

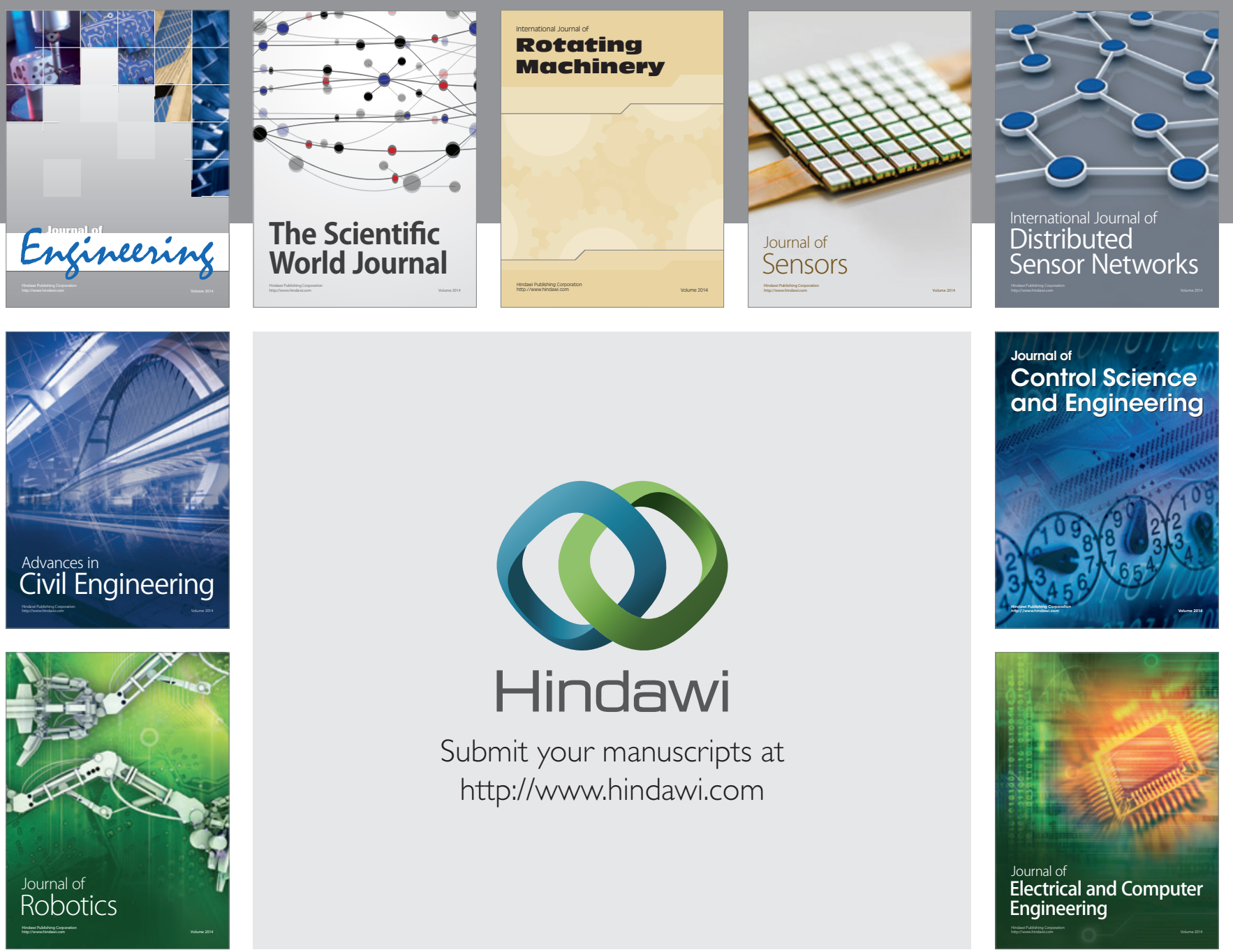

Submit your manuscripts at

http://www.hindawi.com
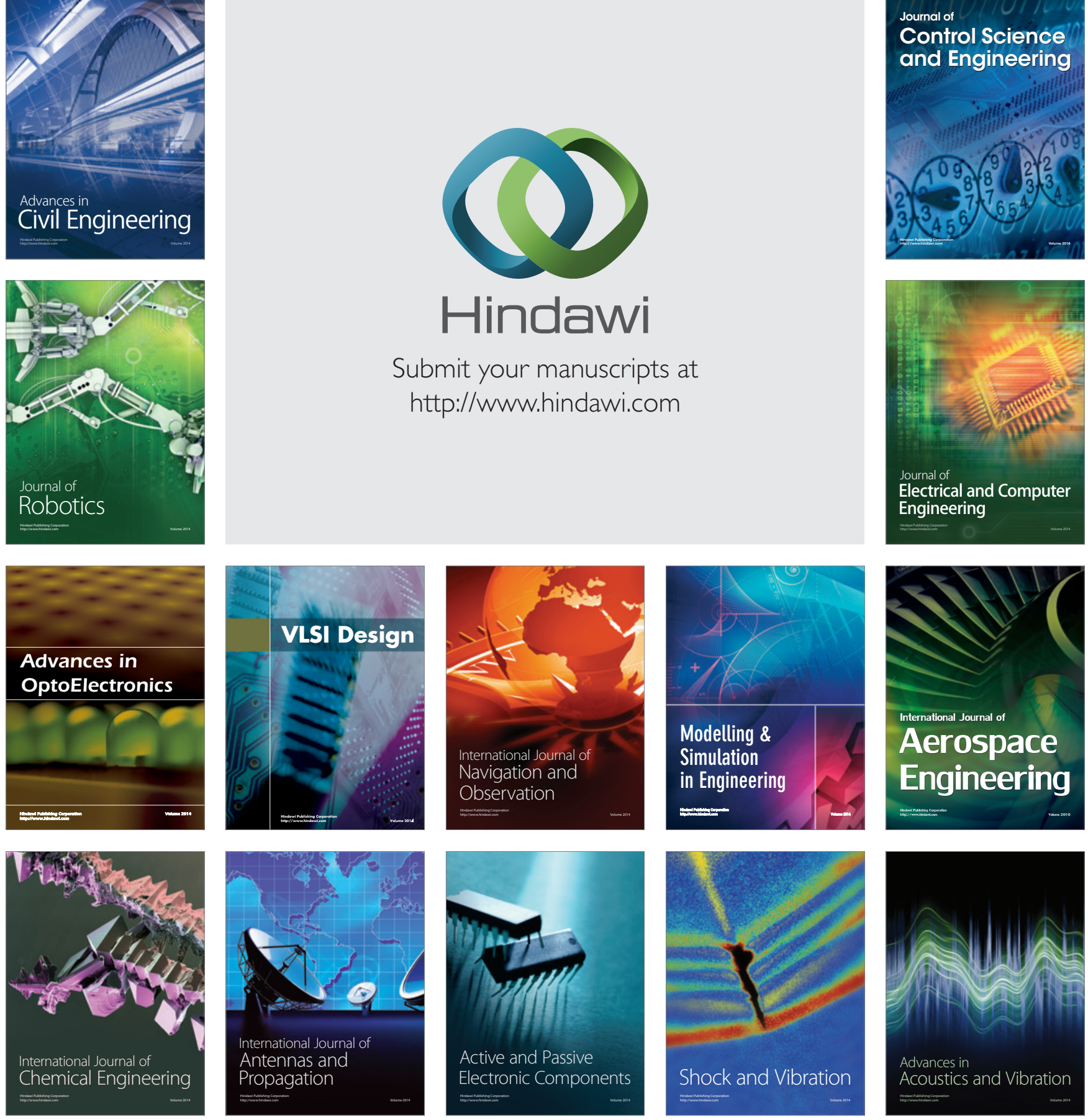